\title{
Indicators of Individual Wine Reputation for Friuli Venezia
}

\section{Giulia}

\author{
Guenter Schamel ${ }^{1} \cdot$ Anna Ros $^{1}$
}

Received: 15 October 2019 / Accepted: 26 November 2020 / Published online: 7 January 2021

(c) The Author(s) 2021

\begin{abstract}
The main objective of this paper is to study indicators of individual wine reputation and how they may affect the price of wines in Friuli Venezia Giulia. The analysis is built on the assumption that consumers base their wine purchase decisions on easily available information such as expert quality ratings and reputation builds on past awards for a wine. We estimate a hedonic pricing model using a data set of 1078 Friulian wines listed in the Gambero Rosso wine guide. The categorical nature of the dependent variable suggests the use of ordered response models. The results not only show that awards for the current quality of a wine carry a positive and substantial premium, but also that having received an award in the past (indicating individual wine reputation) has a positive effect on prices. Moreover, the province of production has a considerable effect on prices and white, older wines tend to be more expensive. The paper confirms the important role of current quality ratings and of individual wine reputation in determining wine prices. An important marketing implication is that wineries and retailers should communicate the current quality of a wine together with any past quality recognitions received as this should foster the reputation of an individual wine in the future.
\end{abstract}

Keywords Hedonic pricing · Reputation · Ordered response models · Wine $\cdot$ Friuli Venezia Giulia

JEL Classification $\mathrm{L} 1 \cdot \mathrm{L} 66 \cdot \mathrm{Q} 13$

Guenter Schamel

guenter.schamel@unibz.it

Anna Ros

rosanna9894@gmail.com

1 Faculty of Economics and Management, Free University of Bozen-Bolzano, Piazza Università 1, 39100 Bozen-Bolzano, Italy 


\section{Introduction}

Many authors have applied hedonic pricing models to wines from different regions of the world to understand which characteristics affect prices and to what extent. Even though hedonic models have been applied to Italian wine regions including Friuli Venezia Giulia (FVG), we add to the literature by estimating a unique ordered logit model using Gambero Rosso wine quality evaluations. Friulian wine is known for its great varietal diversity, quality and its importance, both economically and culturally. According to Corubolo (2013), the production and consumption of wine represent an aspect deeply related to the local culture. Moreover, the focus on quality improvements enabled the wines of the region to remain competitive and to successfully enter the international market. Furthermore, FVG is mainly renowned for its wide range of autochthonous white grape varieties and it is therefore referred to as a unique white wine region in Italy. Given the cultural and economic importance of the wine sector for the region, the development of a hedonic pricing model will help to better understand and assess the impact of different characteristics on the wine price.

In this paper, we analyse a data set of wines from FVG which received a Gambero Rosso Award for 2016. The Gambero Rosso wine guide is commonly recognized as the most important wine guide in Italy. It lists high quality wines for a given calendar year in four award categories (one black glass, two black glasses, two red glasses, three red glasses) and their prices in eight categories. It provides information on wine varieties (e.g. Friulano, Picolit, Ribolla Gialla, Malvasia, Chardonnay, Pinot Grigio, and Sauvignon, as well as other varietals and blends), colour (white, red, rosè), age (from 2 to 12 years), and the provincial origin (Trieste, Udine, Pordenone and Gorizia). In addition, we add any past award levels received in 2014 and 2015 to the data set, serving as a reputation indicator. The nature of the data set and how prices are reported lends the application of limited dependent variable models which are not commonly used in hedonic pricing models for wine. Our main objective is to understand whether Gambero Rosso awards and reputation effects have a significant impact on wine prices, correcting for other quality indicators such as variety, wine colour, age and provincial origin.

In the following section, we present a literature review of selected hedonic pricing models for wine leading to the unique feature of the model developed in this application. Then, we introduce the methodology, the source of the data with summary statistics on the dependent and the independent variables and the hedonic model. Finally, the estimated ordered logit model is illustrated, followed by the interpretation of the results obtained and some concluding remarks. 


\section{Literature Review}

The relationship between wine quality and price has been studied by numerous authors using different methodological approaches and quality indicators. Wine is often regarded as an experience good for which consumers typically cannot assess quality before a purchase. Therefore, economists argue that consumers will rely on product characteristics such as reputation, expert ratings and objective attributes found on the label or otherwise accessible when making a purchase decision. This allows to develop standard hedonic pricing models relating wine prices to differentiated product attributes and to estimate their marginal contribution or implicit price effects. In the literature, many authors have applied hedonic pricing models to wine. Thus, we focus on a selected range of papers in this literature review, leading to the unique feature of our model.

First, we review some of the seminal papers in the wine economics literature applying hedonic pricing. In two papers, Landon and Smith $(1997,1998)$ examine the impact of reputation indicators and current wine quality on the price of Bordeaux wine and discover that long term reputation carries a higher premium than short term quality improvements, which means that consumers value persistent and continuous quality improvements more. Lecocq and Visser (2006) apply the hedonic technique on Bordeaux and Burgundy wines and discover that classification systems or rankings, vintage and appellation (contained in the label) are the major determinants of the price of Bordeaux and Burgundy wines. Moreover, expert ratings or grades have a considerable impact on wine prices but, while these grades are affected by rankings for Burgundy, they are not for Bordeaux. Schamel and Anderson (2003) estimate a hedonic pricing model for premium wine produced in Australia and New Zealand, measuring the impact of sensory quality ratings and regional and winery brand reputations for nine vintages (1992-2000). They suggest that wine prices are highly sensitive to sensory quality ratings, winery ratings and classic wine designations. For Australia, they show that regional reputation is becoming increasingly significant and that wine from cool-climate regions seems to be preferred. We refer to Oczokowski and Doucouliagos (2015) for a comprehensive review over 180 hedonic pricing models on wine. Conducting a meta-regression analysis (MRA) on the size of the quality effect on wine price, they show that there is price-quality relation with a moderate partial correlation of +0.30 . The most important implication of their MRA analysis is the relative importance of wine reputation over sensory quality. Moreover, the results show that the inclusion of producer reputation does not affect the price-quality relationship, which implies that it impacts price directly.

Several authors follow a modified hedonic approach adding to the complexity of different models applied to wine. For example, Nerlove (1995) estimates a model for Sweden, a small wine market without domestic production and monopoly-controlled prices. He estimates a reduced form hedonic price function, regressing quantities sold on quality attributes and prices in a model that assumes wine consumers express their valuation of quality attributes by varying the derived hedonic demand for it. Marangon et al. (2011) employ a multivariate 
logistic model analysing data from the Guida dei Vini del Friuli-Venezia Giulia (editions 2003-2005). They too account for the individual level (wine) as well as for the context level (production area and wine type). Their results show that the dichotomous price is not only affected by the two levels, but also by the proportion of wines considered exceptional among their production areas. Snipes and Taylor (2014) apply the Akaike information criteria (AIC) to compare different models to better understand the relationship between ratings and wine prices. They develop eight different models with ratings as dependent variable and price, varietal, vintage and region of production as independent variables. The best fitting model, with the lowest AIC score, is a simple one with only price and grape varieties as explanatory variables implying that complex models are not always necessary.

Next, we review several hedonic papers regarding Italian wines from specific regions. Benfratello et al. (2009) develop sensorial and reputation models for two premium wines from Piedmont, Barolo and Barbaresco. They use producer reputation indicators as well as single wine reputation indicators from three major Italian wine guides. The comparison between sensorial and reputation models shows that reputation is the main driver of wine prices in the market. Cacchiarelli et al. (2014) apply a hedonic model to Lazio wines and evaluate the impact of quality ratings, number of wine guides reviews, province and certification of origin on wine prices. The analysis is carried out with data from three major Italian guides, namely Gambero Rosso, l'Espresso and AIS (Italian Sommelier Association). Their results show that wine guide ratings are indicators of quality and can be associated with a higher willingness to pay by consumers. Furthermore, experts' ratings may raise prices of both red and white wines and the price of a white wine referenced in all the three guides is significantly higher (Cacchiarelli et al. 2014). Roma et al. (2013) develop a hedonic model to assess the impact of objective, sensory, quality-related and reputational variables on the price of Sicilian wine. The authors use data from Gambero Rosso and Duemilavini and conducted separate hedonic analyses on the two datasets. They employ a log-linear model given the continuous nature of price as the dependent variable. Their results show that consumers regard expert scores as an indicator of current quality. Moreover, receiving good scores over time helps a wine to gain a good reputation, whose importance reflects positively on price.

In line with these papers, there are others that apply ordered response models in their hedonic analysis for Italian wine. Caracciolo et al. (2013) estimate a hedonic pricing model for a specific Italian grape variety, Aglianico, based on data collected from Duemilavini, Gambero Rosso and Veronelli guides. Since prices contained in the guides are expressed in categories, the authors apply an ordered logit model for the analysis. The results of the estimation show that, even though ratings of Gambero Rosso and Veronelli impact positively the wine price, DOC and DOCG appellations affect prices the most. Cacchiarelli et al. (2016) estimate an ordered logit model to explain wine ratings through its attributes and production characteristics.

Two recent studies analyse consumer survey data concerning organic wine preferences. Di Vita et al. (2019) analyse to what extent consumers are willing to pay for organic wines and what characteristics influence its additional price, with respect to other wines. To do so, survey data are used (from Sicilian wine consumers) and 
the ordered logit model is employed for the estimation, with additional price as the dependent variable. The additional price is arranged into five rising levels and it indicates the price premium consumers are willing to pay, in percentage, for organic wines with respect to conventional ones. Results show that consumers are willing to pay more for organic wine and its price premium is affected by individual subjective motives, such as curiosity and label information, rather than by the wine intrinsic characteristics (Di Vita et al. 2019). Mauracher et al. (2019) aim to understand why consumers choose organic wine and what factors influence their prices. They analyse data collected from an online survey among Italian wine consumers. Price being represented by four ordered categories is the dependent variable in an ordinal logistic regression model. According to the results, the willingness to pay differs depending on the market segment and consumers for which price is an important factor for choosing a wine are less willing to pay for organic wine.

\section{Methodology}

In his seminal paper, Rosen (1974) develops the hedonic model and assumes that both consumers and producers make their decisions in order to maximize utility and profits respectively, given the constraints, such as income, price of goods, preferences for substitutes, availability of technology and labour and costs of production. In equilibrium, buyers' indifference or bid curves and sellers' iso-profit or offer curves touch each other along the hedonic price function, optimally matching consumer preferences and producer costs for each product quality attribute (Schamel et al. 1998). As a result, there is no space for improvement, and an optimal and most efficient scenario is reached. The hedonic pricing model associates the price of a good to the features that generate utility for consumers, assigning them implicit prices which reflect buyers' (sellers') marginal willingness to pay (accept).

\subsection{Source of Data}

The aim of this paper is to develop a hedonic analysis applying ordered response models using a uniquely derived data set based on the Gambero Rosso guide Vini d'Italia 2016 containing over 22,000 Italian wines (Gambero Rosso 2015). Using data for wines form Friuli Venezia Giulia, we augment information on current wine quality from this guide with information on the reputation of individual wines from previous editions of the guide. What distinguishes this analysis is the inclusion of a reputation indicator for individual wines having received a similar or higher award in the past and the use of an ordered response model in this context. The information on past awards was collected from the guides Vini d'Italia 2015 (Gambero Rosso 2014) and Vini d'Italia 2014 (Gambero Rosso 2013), matching previous awards for every individual wine receiving a 2016 recognition. More precisely, level of past awards granted by Gambero Rosso in 2014 and 2015 serve as individual short-term reputation indicators for persistent quality. The idea stems from Landon and Smith (1998) who tried to quantify the importance 
Table 1 Price categories

\begin{tabular}{llcc}
\hline Number & Price category $(€)$ & Freq. (count) & Freq. (\%) \\
\hline 1 & $\leq 5$ & 0 & 0.00 \\
2 & $5.01-10.00$ & 197 & 18.27 \\
3 & $10.01-15.00$ & 519 & 48.14 \\
4 & $15.01-20.00$ & 177 & 16.42 \\
5 & $20.01-30.00$ & 128 & 11.87 \\
6 & $30.01-40.00$ & 38 & 3.53 \\
7 & $40.01-50.00$ & 10 & 0.93 \\
8 & $\geq 50.01$ & 9 & 0.83 \\
\hline
\end{tabular}

Source: Data retrieved from Vini d'Italia 2016 (Gambero Rosso) and own calculations

Table 2 Reduced price categories for estimation purposes

\begin{tabular}{llll}
\hline Category & Price range $(€)$ & Freq. (count) & Freq. (\%) \\
\hline 1 & $<=10$ & 197 & 18.27 \\
2 & $10.01-15.00$ & 519 & 48.14 \\
3 & $15.01-20.00$ & 177 & 16.42 \\
4 & $20.01-30.00$ & 128 & 11.87 \\
5 & $>30$ & 57 & 5.29 \\
\hline
\end{tabular}

Source: Data retrieved from Vini d'Italia 2016 (Gambero Rosso) and own calculations

of reputation for Bordeaux wine using relative quality ratings based on overall average ratings as a short-term reputation indicator. The paper studies individual wine reputation and complements the study by Schamel (2009), analysing the relative importance of brand (or winery) reputation in addition to regional effects. Given the ordinal nature of price information in the Gambero Rosso guide (using eight price categories), an ordered response model is used to determine the impact of the independent variables on wine prices. As independent variables we include easily available information from a current wine guide identifying current wine quality, origin of production, wine variety, colour, wine age, and the derived short-term individual wine reputation indicator from past guides.

In the Gambero Rosso guide Vini d'Italia 2016, wines from Friuli Venezia Giulia accounted for 1102 observations, reduced by the authors to 1078 as 24 wines carry no vintage information. For every wine receiving an award, the guide provides information about its colour, vintage, producer, province of production and price category, from 1 to 8 . From Table 1, we see that almost half of the wines (48\%) have a price between $€ 10.01$ and $€ 15$ and no wine has a price lower than $€ 5$. In order to make the estimates more robust, the authors reduced the categories from 8 to 5 , according to Table 2. Note that the varietal information was retrieved from the wine name. Finally, using the guides of the two previous years, we determine whether the same wine received an award in 2014 and 2015 of the same or higher level. 
Table 3 Summary statistics of independent variables

\begin{tabular}{|c|c|c|c|}
\hline \multirow[t]{2}{*}{ Independent variables } & \multirow[t]{2}{*}{ Parameters } & \multicolumn{2}{|c|}{ Frequency } \\
\hline & & Count & $\begin{array}{l}\text { Relative } \\
(\%)\end{array}$ \\
\hline \multirow[t]{4}{*}{ Award } & 1 black glass $^{\mathrm{a}}$ & 250 & 23.19 \\
\hline & 2 black glasses & 695 & 64.47 \\
\hline & 2 red glasses & 109 & 10.11 \\
\hline & 3 red glasses & 24 & 2.23 \\
\hline \multirow[t]{4}{*}{ Province } & Trieste (TS) & 21 & 1.95 \\
\hline & Udine $(\mathrm{UD})^{\mathrm{a}}$ & 563 & 52.23 \\
\hline & Gorizia (GO) & 428 & 39.70 \\
\hline & Pordenone (PN) & 66 & 6.12 \\
\hline \multirow[t]{3}{*}{ Color } & White & 755 & 70.04 \\
\hline & $\operatorname{Red}^{\mathrm{a}}$ & 319 & 29.59 \\
\hline & Rosè & 4 & 0.37 \\
\hline \multirow[t]{3}{*}{ Age } & 2 years & 553 & 51.30 \\
\hline & 3 years & 233 & 21.61 \\
\hline & $4-10$ years & 292 & 27.09 \\
\hline \multirow[t]{2}{*}{ Past award level } & Award level 2014 & 458 & 42.49 \\
\hline & Award level 2015 & 550 & 51.02 \\
\hline
\end{tabular}

Source: Data retrieved from Vini d'Italia 2016, 2015, 2014 and own calculations

${ }^{\mathrm{a}}$ Indicates the base category

The independent variables (see Table 3), are award, province, wine variety, colour, age, 2014 award level and 2015 award level. Except for age, the other variables in the model are dummies or categorical dummies.

Award: the national guide Vini d'Italia 2016 (Gambero Rosso 2015, p. 24) classifies the wines assigning four types of awards: one black glass, meaning that the wine is good within its category, two black glasses, stating that the wine is very good or exceptional within its category, two red glasses, indicating very good or exceptional wine that reached the final tasting and three red glasses, awarded to excellent wines within their respective categories. As you can see from Table 3, nearly $65 \%$ of the wines received two black glasses, but only $2 \%$ was awarded with the three red glasses. Even though the percentage of wines classified as excellent is small, the best white wine of the year award was given to a Friulian wine, the "Collio Friulano "14" produced by Schiopetto.

Province: the wines are grouped according to the regions of production, corresponding to the provinces of Trieste (TS), Udine (UD), Gorizia (GO) and Pordenone $(\mathrm{PN})$. Many of the wines awarded are produced in the provinces of Udine and Gorizia (see Table 3). For a more detailed distribution of the Gambero Rosso awards by province, please refer to Table 4 .

Wine variety: the region Friuli Venezia Giulia is characterized by a wide variety of wines, a feature reflected by the data set, containing more than thirty wine 


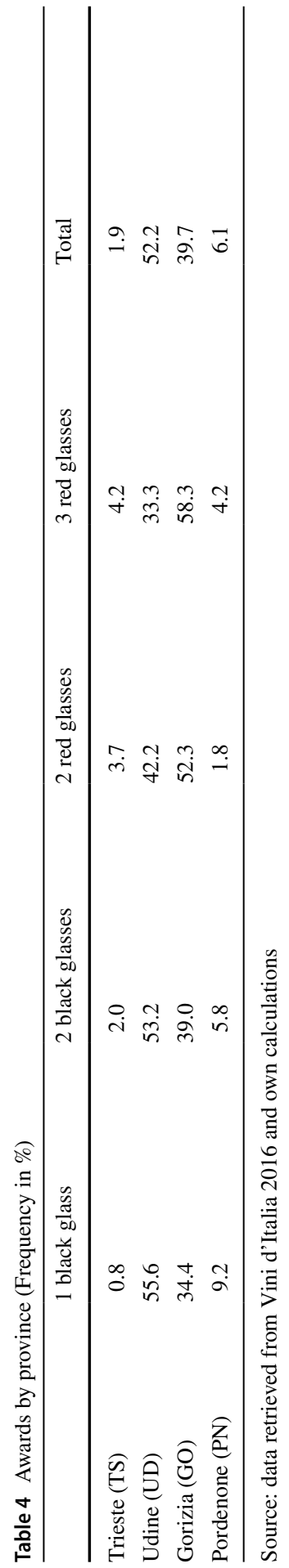




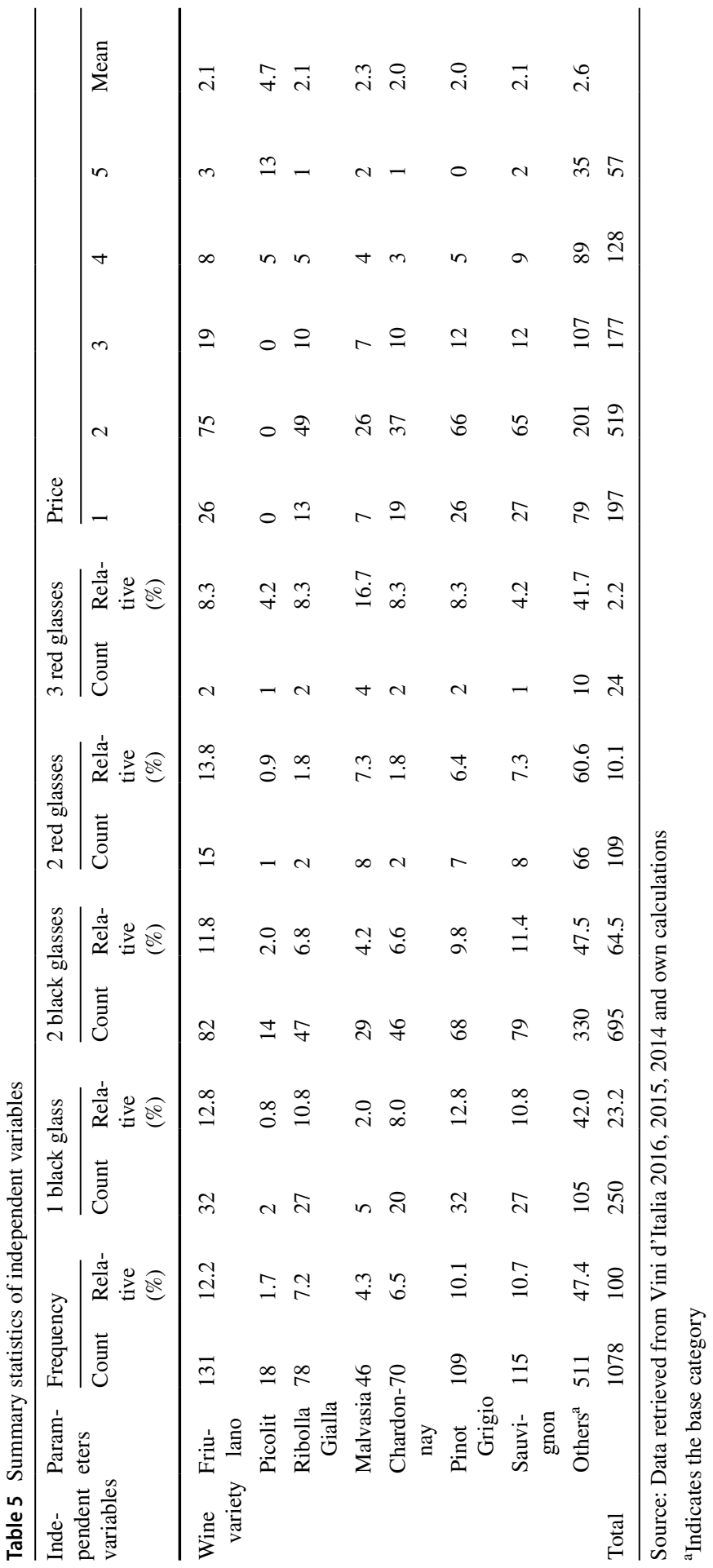


varieties, such as the typical whites Friulano, Ribolla Gialla, Malvasia, Pinot Grigio, Sauvignon, Chardonnay and the exclusive sweet white wine Picolit. "Others" stands for all the other white and red varieties of FVG wines, such as Cabernet, Merlot, Refosco and Pinot Bianco (Table 5).

Wine colour and age: as you can see from Table 3, most wines (70\%) are white wines with Friulano, Pinot Grigio and Sauvignon as most common varieties. In addition, even though the data set contains wines with two to twelve years, a considerable portion belongs to the 2014 vintage.

Reputation (past award levels): according to the data of the Gambero Rosso guides Vini d'Italia 2014 and Vini d'Italia 2015, more than half of the wine awarded in 2016 had received an award also in 2014 and/or 2015. As shown in Table 3, approximately half of the wines awarded in 2016 won an award of the same or higher level in one of the two previous years. Therefore, it appears that reputation plays an important role in determining future awards, meaning that a wine that has already received an award in the past is more likely to be awarded again.

\subsection{Hedonic Price Model}

Different functional forms and modelling approaches have been adopted in order to estimate the hedonic models, depending on the nature of the dependent variable. Following Caracciolo et al. (2013) and Cacchiarelli et al. (2016), we apply the ordered logit model given the ordinal nature of the dependent variable and use Stata in the estimation.

Given the not continuous nature of the dependent variable, it was not possible to use the standard multivariate regression model. For our data set, the dependent variable $y_{i}$ is ordinal and in fact $y_{i}=2,3,4,5$, such that we employ ordered dependent variable models. For such models, the dependent variable is related to the index function (1):

$$
y_{i}^{*}=x_{i}^{\prime} \beta+\varepsilon_{i}
$$

which assumes a linear dependence between $y_{i}^{*}$ and $x_{i}$ and random disturbance $\varepsilon_{i}$ with zero mean. The observed $y_{i}$ is computed starting from the index function using the following rule:

$$
y_{i}=\left\{\begin{array}{lll}
0 & \text { if } & y_{i}^{*} \leq \gamma_{1} \\
1 & \text { if } & \gamma_{1}<y_{i}^{*} \leq \gamma_{2} \\
2 & \text { if } & \gamma_{2}<y_{i}^{*} \leq \gamma_{3} \\
\cdot & & \\
\cdot & & \\
M & \text { if } & \gamma_{M}<y_{i}^{*}
\end{array}\right.
$$

Given the ordinal nature of the dependent variable, the ordering must be preserved. Therefore, both $y_{i}^{*}<y_{j}^{*}$ and $y_{i}<y_{j}$ must hold (IHS Global Inc 2017). 
Consequently, the probabilities associated to each value of the dependent variable are defined by:

$$
\begin{aligned}
& P\left(y_{i}=0 \mid x_{i}, \beta, \gamma\right)=F\left(\gamma_{1}-x_{i}^{\prime} \beta\right) \\
& P\left(y_{i}=1 \mid x_{i} \beta, \gamma\right)=F\left(\gamma_{2}-x_{i}^{\prime} \beta\right)-F\left(\gamma_{1}-x_{i}^{\prime} \beta\right) \\
& P\left(y_{i}=2 \mid x_{i}, \beta, \gamma\right)=F\left(\gamma_{3}-x_{i}^{\prime} \beta\right)-F\left(\gamma_{2}-x_{i}^{\prime} \beta\right) \\
& \cdots \\
& P\left(y_{i}=M \mid x_{i}, \beta, \gamma\right)=1-F\left(\gamma_{M}-x_{i}^{\prime} \beta\right)
\end{aligned}
$$

According to Heij et al. (2004, pp. 475-476), the unknown parameters that need to be estimated are the coefficients $\beta$ and the threshold values $\gamma$. In order to esti-

\begin{tabular}{|c|c|c|c|}
\hline Variable & Parameter & Coefficient & Significance \\
\hline \multirow[t]{3}{*}{ Award } & 2 black glasses & 0.836 & $* * *$ \\
\hline & 2 red glasses & 2.134 & $* * *$ \\
\hline & 3 red glasses & 2.663 & $* * *$ \\
\hline \multirow[t]{3}{*}{ Province } & Pordenone (PN) & -1.763 & $* * *$ \\
\hline & Trieste (TS) & 1.429 & $* * *$ \\
\hline & Gorizia (GO) & 0.684 & $* * *$ \\
\hline \multirow[t]{7}{*}{ Wine variety } & Friulano & -0.452 & $* *$ \\
\hline & Picolit & 4.810 & $* * *$ \\
\hline & Ribolla Gialla & -0.084 & \\
\hline & Malvasia & -0.666 & $* *$ \\
\hline & Chardonnay & -0.577 & $* *$ \\
\hline & Pinot Grigio & -0.637 & $* * *$ \\
\hline & Sauvignon & -0.363 & \\
\hline Colour & White & 0.805 & $* * *$ \\
\hline \multirow[t]{2}{*}{ Reputation } & 2014 award level & 0.581 & $* * *$ \\
\hline & 2015 award level & 0.504 & $* * *$ \\
\hline \multirow[t]{2}{*}{ Age } & Age & 0.996 & $* * *$ \\
\hline & & & Std. Error \\
\hline \multirow[t]{4}{*}{ Thresholds } & Cut1 & 2.671 & 0.316 \\
\hline & Cut2 & 5.759 & 0.350 \\
\hline & Cut3 & 7.223 & 0.380 \\
\hline & Cut4 & 9.410 & 0.451 \\
\hline
\end{tabular}
mate these parameters, the maximum likelihood (ML) estimator (4) should be used.

Table 6 Ordered logistic regression results
No. Obs $=1078 ; \log$ likelihood $=-1138.5913 ;$ LR $\operatorname{chi} 2(17)=671.43$; Prob $>$ chi $2=0.0000$

Pseudo $\mathrm{R}^{2}=0.2277$; significance levels are $10 \%(*), 5 \%(* *)$ and $1 \%$ $(* * *)$

Source: own calculations 
Using ML, these parameters are estimated in a way to maximize the likelihood and probability of the observed data (cf. Heij et al. 2004, p. 222).

$$
l(\beta, \gamma)=\sum_{i=1}^{N} \sum_{j=0}^{M} \log \left(P\left(y_{i}=j \mid x_{i}, \beta, \gamma\right)\right) \cdot 1\left(y_{i}=j\right)
$$

At this stage, the F function should be described by using either the standard normal or the logistic distributions, which are referred to as the ordered probit and the ordered logit models respectively (cf. Heij et al. 2004, pp. 476-477). Following Heij et al. (2004), there is no specific reasons to choose the probit over the logit model or vice versa.

\subsection{Estimated Ordered Logit Model}

Given the ordinal nature of the dependent variable, the ordered logit model is estimated in the following way:

$$
P\left(\text { price }=M \mid x_{i}, \beta, \gamma\right)=F\left(\gamma_{M+1}-x_{i}^{\prime} \beta\right)-F\left(\gamma_{M}-x_{i}^{\prime} \beta\right)
$$

with

$$
\begin{aligned}
x_{i}^{\prime} \beta= & \beta_{1} D_{\text {i2blackglasses }}+\beta_{2} D_{\text {i2redglasses }}+\beta_{3} D_{\text {i3redglasses }} \\
& +\beta_{4} D_{i P N}+\beta_{5} D_{i T S}+\beta_{6} D_{i G O}+\beta_{7} D_{\text {iFriulano }} \\
& +\beta_{8} D_{\text {iPicolit }}+\beta_{9} D_{\text {iRibollaGialla }}+\beta_{10} D_{\text {iMalvasia }}+\beta_{11} D_{\text {iChardonnay }} \\
& +\beta_{12} D_{\text {iPinotGrigio }}+\beta_{13} D_{\text {iSauvignon }}+\beta_{14} D_{\text {iWhite }}+\beta_{15} D_{i 2014 \text { awardlevel }} \\
& +\beta_{16} D_{\text {i2015awardlevel }}+\delta \text { Age }
\end{aligned}
$$

The dependent variable is the price, while the explanatory variables are the dummy variables $D_{i}$ and the regular variable $A g e_{i}$. In the estimated logit model (5), the coefficients $\beta_{i}=\left(\beta_{1}, \beta_{2}, \ldots, \beta_{16}\right)$ are associated to each dummy variable, while $\delta$ is related to the regular variable age. In more detail, $\beta_{1}, \beta_{2}, \beta_{3}$ refer to each parameter of the categorical dummy award, $\beta_{4}, \beta_{5}, \beta_{6}$ to each one of the categorical dummy province, $\beta_{7}, \beta_{8}, \beta_{9}, \beta_{10}, \beta_{11}, \beta_{12}, \beta_{13}$ to each one of the categorical dummy wine variety, $\beta_{14}$ to the white parameter of the color dummy, $\beta_{15}$ and $\beta_{16}$ to the regular dummies 2014 and 2015 award level respectively and $\delta$ to the regular variable age. The rosé parameter could not be included in the model since the number of observations of rosé wine is lower than the number of regressors.

The output of the ordered logit model consists of the estimated coefficients $\widehat{\delta}$ and $\left.\widehat{\beta}_{i}=\widehat{\left(\beta_{1}\right.}, \widehat{\beta}_{2}, \ldots, \widehat{\beta_{16}}\right)$ related to the parameters, as well as of the coefficients associated to each threshold, used to compute the probabilities associated to each value of the dependent variable. 


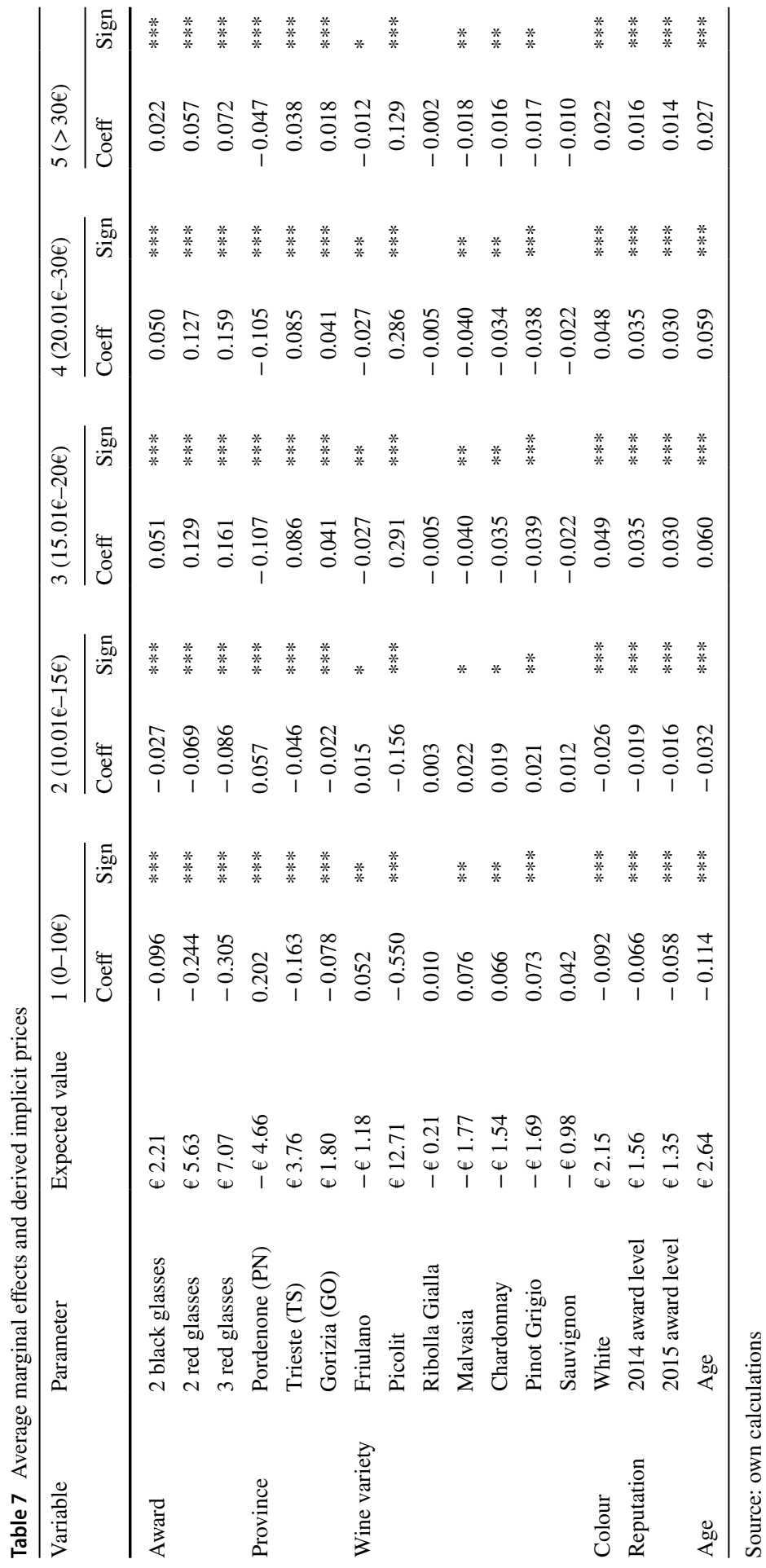




\section{Results}

The results of the ordered logit model (included in Table 6) are obtained by estimating Eq. (5) using Stata.

At a confidence level of $10 \%$, all the explanatory variables are statistically significant, except for Ribolla Gialla and Sauvignon. Experts awards and reputation indicators have a positive impact on price. Also, age and white colour influence price positively. As for province of production, results show that Pordenone has a negative impact on price, while Gorizia and Trieste a positive one. For what concerns wine variety, Picolit has the greatest positive effect on price, while Friulano, Malvasia, Chardonnay and Pinot Grigio influence price negatively. Overall, Picolit, 2 and 3 red glasses have the greatest positive impact on wine price.

For ordered logit models, marginal effects are interpreted as the impact of a unit increase in an independent variable on the probability of moving to the next highest price category. In order to calculate implicit prices, the probability change is transformed into the average change of a wines' expected value as outlined in Caracciolo et al. (2013). As reported in Table 7, receiving 2 and 3 red glasses increases the average market price by $€ 5$ and $€ 7$ respectively. Wine produced in the province of Trieste results to be more expensive with respect to wine produced in Udine (around $€ 3$ ), while Pordenone carries a substantial discount (around-€4). As single variety wines, Friulano, Malvasia, Chardonnay and Pinot Grigio show a significant negative effect on the average market price relative to the base category representing all other wine varieties and blends typical for the region. Note that Picolit is a unique autochthonous grape used to make a peculiar passito style wine with limited substitutability that is sold in a different price range compared to other white wines in the sample. The variety dummy is highly significant in the model with an implicit price effect of about $€ 12$ compared to the effect of the white wine dummy variable which has an implicit price of about $€ 2$. Finally, wines that received an award of the same or higher level in the past two years result to be more expensive, given the derived implicit price between $€ 1.30$ and $€ 1.50$. Moreover, ageing has a significant effect in our sample of more than $€ 2.50$ per year. As we have set up our model including past awards as an individual reputation indicator and current awards as a quality premium, we can interpret the results as follows: having received an award in the past is an important signal for consumers in the market, while the current quality premium signals that this reputation is being upheld. Moreover, in addition to rewarding the quality of a wine currently on sale, the award premium together with a past award premium also signals that the same wine gains a reputation premium when it receives further awards in the future. 


\section{Summary and Conclusion}

This paper contributes to the existing literature on Italian wines, given the importance of the wine sector and culture for the Italian region Friuli Venezia Giulia. The main goal was to evaluate the impact on wine prices of current quality of an individual wine and derived short-term reputation indicators from previous awards it received. In order to do so, we employed ordered response models with a unique data set that includes past award levels retrieved from the renowned Gambero Rosso guide.

We estimated an ordered logit model and the estimated coefficient indicate that the price of wines produced in FVG depends significantly on current quality ratings (2016 award level) and on the individual wine reputation (expressed through past award levels) raising the average market price. These results are coherent with the previous literature emphasizing the important role of current quality and reputation indicators in determining wine prices. While awards received in the past carry a significant price effect, the current quality effect is higher as it signals individual wine reputation continues to be upheld. From this result, we can draw an important marketing implication: In addition to emphasizing the quality of a wine currently on sale, it is very important to stress whether the same wine has received awards in the past. Together, this information lends credibility to the reputation of an individual wine in the future.

The models also show that white wines carry a significant premium relative to reds and rosés which is a relative unique finding in the literature, underscoring the high quality of the whites from Friuli Venezia Giulia. Also, the province of production plays a crucial role in determining wine prices. This means that in addition to individual reputation, renowned provinces of Gorizia and Trieste carry a regional reputation that is reflected in wine prices. Moreover, wine age is another important price determinant. The estimated coefficient implies that producers should sell wines with ageing potential at the right time as another year of storage could add significant revenue.

In terms of the varieties examined, Picolit is the only one receiving a significantly positive price premium compared to the base category represented by other varietals and blends. It follows from its unique autochthonous character and the passito style wines made sold at prices reaching $€ 50$ and more. Note that relative to the base category of the model which represents all other wine varieties and blends typical for the region, the single variety wines from Friulano, Malvasia, Chardonnay and Pinot Grigio grapes exhibit a negative price effect. Thus, these single variety wines do not receive a comparable price relative to other wine varieties and blends typical for the region. The only single variety wines that receive a comparable price relative to the base category are Sauvignon and Ribolla Gialla.

Finally, we note the exploratory nature of this paper to the extent that it looks at reputation effects from awards received in two previous years and that the analysis is limited to wines from Friuli Venezia Giulia. Further research may extend the analysis by looking at the dynamics suggested by our model, i.e. how current 
awards become past awards and translate into reputation indicators. In addition, further work should analyse how this process plays out over time for wines from other Italian regions and beyond. Moreover, the price effects of ageing could be investigated over time in conjunction with reputation indicators given a suitably large data set. This may lead to a better understanding how experts' ratings for current quality, reputation indicators representing past quality and ageing affect the prices for Italian wines and to identify similarities and differences between Italian wine regions in this regard.

Funding Open access funding provided by Libera Università di Bolzano within the CRUI-CARE Agreement.

Open Access This article is licensed under a Creative Commons Attribution 4.0 International License, which permits use, sharing, adaptation, distribution and reproduction in any medium or format, as long as you give appropriate credit to the original author(s) and the source, provide a link to the Creative Commons licence, and indicate if changes were made. The images or other third party material in this article are included in the article's Creative Commons licence, unless indicated otherwise in a credit line to the material. If material is not included in the article's Creative Commons licence and your intended use is not permitted by statutory regulation or exceeds the permitted use, you will need to obtain permission directly from the copyright holder. To view a copy of this licence, visit http://creativecommons.org/licen ses/by/4.0/.

\section{References}

Benfratello L, Piacenza M, Sacchetto S (2009) Taste or reputation: what drives market prices in the wine industry? Appl Econ 41(17):2197-2209

Cacchiarelli L, Carbone A, Laureti T, Sorrentino A (2014) The value of quality clues in the wine market: evidences from Lazio, Italy. J Wine Res 25(4):281-297. https://doi.org/10.1080/09571 264.2014.959659

Cacchiarelli L, Carbone A, Esti M, Laureti T, Sorrentino A (2016) Assessing Italian wine quality and prices: de gustibus non disputandum est. Br Food J 118(5):1006-1024. https://doi.org/10.1108/ BFJ-03-2015-0108

Caracciolo F, Cembalo L, Pomarici E (2013) The hedonic price for an Italian grape variety. Ital J Food Sci 25(3):289-294

Corubolo E (2013) Dimensione Economica e Specializzazioni dell'Agricoltura del Friuli-Venezia Giulia al 2010: Il Censimento dell'agricoltura 2010, nuove prospettive di analisi. Istituto nazionale di statistica, Rome

Di Vita G, Pappalardo G, Chinnici G, La Via G, D’Amico M (2019) Not everything has been still explored: Further thoughts on additional price for organic wines. J Clean Prod 231:520-528

Gambero Rosso (2013) Vini d'Italia 2014. Rotolito Lombarda, Milano

Gambero Rosso (2014) Vini d'Italia 2015. Omnimedia S.r.1, Rome

Gambero Rosso (2015) Vini d'Italia 2016. Omnimedia S.r.1, Rome

Heij C, de Boer P, Frances PH, Kloek T, Van Dijk HK (2004) Econometrics methods with applications in business and economics. Oxford University Press, Oxford

IHS Global Inc. (2017) Eviews 10 Users' Guide II, Irvine. http://www.eviews.com/help/content/prefa ce.html\#. Accessed 30 May 2018

Landon S, Smith CE (1997) The use of quality and reputation indicators by consumers: the case of bordeaux wine. J Consum Policy 20(3):289-323

Landon S, Smith CE (1998) Quality expectations, reputation, and price. S Econ J 64(3):628-647

Lecocq S, Visser M (2006) What determines wine prices: objective vs. sensory characteristics. J Wine Econ 1(1):42-56

Marangon F, Pagani L, Troiano S, Zaccomer GP (2011) Il Prezzo dei vini di qualità del Friuli-Venezia Giulia: una prima analisi dei dati di fonte camerale. Economia Agro Alimentare 1(2):509-514 
Mauracher C, Procidano I, Valentini M (2019) How product attributes and consumer characteristics influence the WTP, resulting in a higher price premium for organic wine. Sustainability 11(1428):1-15

Nerlove M (1995) Hedonic price functions and the measurement of preferences: the case of Swedish wine consumers. Eur Econ Rev 39:1697-1716

Oczkowski E, Doucouliagos H (2015) Wine prices and quality ratings: a meta-regression analysis. Am J Agric Econ 97(1):103-121

Roma P, Di Martino G, Perrone G (2013) What to show on the wine labels: a hedonic analysis of price drivers of Sicilian wines. Appl Econ 45(19):2765-2778

Rosen S (1974) Hedonic prices and implicit markets: product differentiation in pure competition. J Polit Econ 82(1):34-55

Schamel G (2009) Dynamic analysis of brand and regional reputation: the case of wine. J Wine Econ 4(1):62-80

Schamel G, Anderson K (2003) Wine quality and varietal, regional and winery reputations: hedonic prices for Australia and New Zealand. Econ Rec 79(246):357-369

Schamel G, Gabbert S, von Witzke H (1998) Wine quality and price: a hedonic approach. In: Pick et al. Global markets for processed foods: theoretical and practical issues, pp 211-221

Snipes M, Taylor DC (2014) Model selection and Akaike information criteria: an example from wine ratings and prices. Wine Econ Policy 3(1):3-9 